\title{
As características dos empreendimentos sociais atuantes na economia solidária em diferentes países da América Latina
}

The characteristics of social enterprise active in the solidarity economy in various countries of Latin America

\section{Resumo}

O presente artigo tem como objetivo identificar as características e a concepção de economia solidária de empreendimentos sociais de diferentes países participantes da $2^{a}$ Feira Mundial de Economia Solidária. Quanto ao método, o estudo classifica-se como uma pesquisa descritiva com abordagem qualitativa. Para a coleta de dados primários utilizou-se de entrevistas semiestruturadas, aplicadas junto aos representantes de quatro empreendimentos da América Latina, sendo eles: Peru, Argentina, Uruguai e Brasil. Dentre os principais resultados tem-se que a maioria dos entrevistados considera a economia solidária um fenômeno social que resulta em trabalho coletivo, autogestão, equidade e solidariedade o que vem ao encontro dos ditames da teoria. Aliado a isto, destaca-se a importância das feiras como ponto de comercialização de produtos e troca de informações.

Palavras-chave: Economia solidária, Empreendedorismo social, Feira mundial de economia solidária.

\begin{abstract}
This article aims to identify the characteristics and the design of social economy social enterprises from different countries participating in the 2nd World Fair of Solidarity Economy. As for the method, the study is classified as a descriptive qualitative approach. For the collection of primary data was used semi-structured interviews, applied together with representatives from four projects in Latin America, namely, Peru, Argentina, Uruguay and Brazil. Among the key findings is that the majority of respondents consider the social economy a social phenomenon that results in collective work, self-management, equity and solidarity which meets the dictates of theory. Allied to this, we highlight the importance of trade as a point of marketing products and information exchange.
\end{abstract}

Keywords: Solidarity economy, Social entrepreneurship, 2nd World Fair of Solidarity Economy.

Recebido: 09/12/2016 Aceito: 29/05/2017

Maríndia Brachak dos Santos ${ }^{1}$, Tatiane Lopes Duarte ${ }^{2}$, Maíra Nunes Piveta ${ }^{3}$, Flavia Luciane Scherer ${ }^{4}$, Lúcia Rejane da Rosa Gama Madruga ${ }^{5}$

${ }^{1}$ Professora Assistente no colégio Politécnico da UFSM. Doutoranda no Programa de Pós-Graduação em Administração/UFSM, Mestra em Administração - PPGA/UFSM, Graduada em Ciências Contábeis - UNOCHAPECÓ marindiabrachak@gmail.com - Av. Madianeira, 901 SM - RS - CEP 97060-003

${ }^{2}$ Doutoranda no Programa de Pós-Graduação em Administração/UFSM, Mestra em Administração - PPGA/UFSM Administradora - UNIFRA - tatiduarte.80@gmail.com

${ }^{3}$ Bacharel em Administração pela Universidade Federal de Santa Maria (UFSM) - mairapivetasm@ @otmail.com

${ }^{4}$ Graduada em Administração na Universidade Federal de Santa Maria (UFSM) - flaviascherer@globo.com

${ }^{5}$ Graduada em Administração pela Universidade Federal de Santa Maria. Licenciatura Plena Em Matemática - Centro Universitário Franciscano. Mestre em Engenharia de Produção pela Universidade Federal de Santa Maria e doutorado em Agronegócios pela Universidade Federal do Rio Grande do Sul - luciagm@ufsm.br 


\section{Introdução}

O quadro de desigualdades, injustiças e desemprego faz emergir os empreendimentos inseridos no contexto da economia solidária. Estes empreendimentos possuem uma perspectiva de construir uma economia mais justa e igualitária, que procura incluir pessoas excluídas da sociedade, seja no âmbito econômico ou social, como é o caso, por exemplo, dos movimentos sociais em prol da autonomia das mulheres que pregam a sua participação ativa em comunidade.

Neste sentido, torna-se relevante que a comunidade acadêmica desenvolva mais pesquisas sobre a temática da economia solidária buscando a compreensão deste fenômeno social que inclui aspectos de diferentes áreas, tais como a administração, a sociologia, a psicologia, a economia, entre outras.

Diante disto, este estudo teve como objeto de análise os empreendimentos de economia solidária que participaram da $2^{\mathrm{a}}$ Feira Mundial de Economia Solidária em Santa Maria/RS. O estudo foi desenvolvido com o objetivo de identificar a concepção de economia solidária para empreendimentos sociais participantes da $2^{\mathrm{a}}$ Feira Mundial de Economia Solidária assim como identificar suas características empreendedoras sociais. Foram realizadas entrevistas com representantes do Peru, Argentina, Uruguai e Brasil.

Este trabalho se encontra estruturado em quatro seções, além desta introdução. A primeira apresenta o aporte teórico sobre economia solidária, empreendedorismo social e uma visão sobre o lócus do estudo, a segunda seção trata dos procedimentos metodológicos do estudo. Logo após, apresentam-se as análises, discussão dos resultados e as considerações finais da pesquisa.

\section{Economia Solidária}

O surgimento da economia solidária deve-se à necessidade de se manter na política neoliberal, uma maneira dos pequenos empreendimentos sobreviverem frente aos grandes. Surge como modo de produção e distribuição alternativo ao capitalismo, criado e recriado pelos que se encontram (ou temem ficar) marginalizados do mercado de trabalho (SINGER; SOUZA, 2000). Segundo esses mesmos autores a economia solidária:

...não é criação intelectual de alguém, embora os grandes autores socialistas denominados "utópicos" da primeira metade do século XIX (Owen, Fourier, Buchez, Proudhon etc.) tenham dado contribuições decisivas ao seu desenvolvimento. A economia solidária é uma criação em processo contínuo de trabalhadores em luta contra o capitalismo. Como tal, ela não poderia preceder o capitalismo industrial, mas o acompanha como uma sombra, em toda sua evolução (SINGER; SOUZA, 2000, p.13).

A economia solidária assume diferentes concepções no mundo, fato que pode ser constatado ao passo que na América Latina ela assume a forma de cooperativa, bancos populares, clubes de trocas e associações e na Europa consolida-se por meio de cooperativas e empresas sociais, sistemas de trocas, entre outras formas organizacionais (FRANÇA FILHO; LAVILLE, 2004).

Andion (2005) salienta que o fortalecimento da sociedade civil é um fato central para a compreensão do surgimento da economia solidária em diferentes países. Neste contexto de novos significados políticos, econômicos e sociais, emergem com toda a força as organizações "solidárias" em diferentes regiões do mundo. A perspectiva de uma economia solidária supõe outro olhar em relação à economia real. Não apenas focada no mercado, mas uma economia que admite uma pluralidade de princípios do comportamento econômico. A economia plural permite dar conta de uma ampla dimensão da vida econômica, em especial, daquela regida prioritariamente pela solidariedade, esquecida pela teoria econômica neoclássica (FRANÇA, 2003).

A adesão dos trabalhadores a alternativas de geração de renda, de caráter associativo e cooperativo, configura gradativamente a economia solidária como um novo campo de práticas (GAIGER, 2004). Nesta linha de pensamento, Coutinho et al.,(2005) infere que a economia solidária proporciona para os participantes um local de diálogo, solidariedade e cooperativismo, onde os sujeitos se envolvem na luta contra a opressão, injustiça e desigualdade.

A economia solidária originou-se da ajuda de pessoas carentes e excluídas da economia de mercado, não tendo acesso aos bens produtivos, aos serviços, à tecnologia e ao crédito quando foram criadas as cooperativas, que "são sociedades de pessoas, organizadas em bases democráticas, que visam não só a suprir seus membros de bens e serviços, como também a realizar determinados programas educativos e sociais" (PINHO, 2004, p. 124).

Para Roca (2012) uma característica fundamental da economia solidária é o reconhecimento do trabalho humano em sua capacidade de gerar riqueza na sociedade, cultura e ética nas relações. Nesse contexto Tauile (2002) caracteriza os traços da economia solidária como: a reciprocidade colocada no cerne de sua ação econômica; vontade coletiva de empreender; gênese e os atores 
envolvidos; ela se dá no âmbito de uma dinâmica cidadã favorecendo a criação de espaços públicos de proximidade e geração de renda.

A economia solidária diferencia-se da empresa capitalista, porque, no seu contexto, existe um processo de mudança de paradigma, no qual o participante adota uma postura de cooperador, membro de um coletivo, responsável com o grupo das tomadas de decisões, sendo cada um responsável por si e pelos demais, aumentando os conhecimentos relativos ao social, econômico, afetivo e ideológico (LANGE, 2009).

O quadro promissor da economia solidária para Gaiger (2004) além de carrear rapidamente o apoio de ativistas, organizações sociais e órgãos públicos, fomentou um interesse sobre o problema da viabilidade desses empreendimentos, bem como sobre a natureza e o significado contido nos seus traços sociais, de socialização dos bens de produção e do trabalho.

\section{Empreendedorismo Social}

O termo empreendedorismo é utilizado há muito tempo, pode-se dizer que desde a Idade Média, sendo associado, mais comumente, à abertura e administração de empresas com o intuito de gerar lucro e renda. De acordo com Melo Neto e Froes (2002, p.6) "empreendedorismo é um neologismo derivado da livre tradução da palavra entrepreneurship, sendo utilizado para designar os estudos relativos ao empreendedor, seu perfil, suas origens, seu sistema de atividades, seu universo de atuação".

No entanto, ao longo dos séculos, com as constantes transformações que vem ocorrendo nas sociedades, principalmente a partir do século XX, uma nova visão de mundo começa a emergir. Neste novo cenário o empreendedor social passou a ocupar posição notória, uma vez, que em virtude de suas características singulares, agrega valor à sociedade (OLIVEIRA, 2004).

O empreendedorismo social é tido como um fenômeno mundial, sendo o empreendedor social visto como o responsável na busca de soluções para os mais variados problemas sociais, apresentando-se como um agente ativo e transformador dos valores da sociedade. Nesse sentido, Madruga (2009, p.140) pondera que o empreendedorismo social carrega "a inovação como um componente essencial de sua definição, ou seja, para resolver problemas sociais é necessário desenvolver iniciativas com potencial de inovação social transformadora de uma realidade local, nacional ou mundial".

De acordo com o exposto, Melo Neto e Froes (2002) relatam que com o crescimento dos problemas sociais, o que gerou o paradigma da exclusão social, tornou-se imprescindível o desenvolvimento de uma nova atitude de todos os atores políticos e sociais. Atitude esta que precisa ser inovadora em sua natureza e essência, voltada para o desenvolvimento sustentável das comunidades em geral, e, sobretudo, das comunidades de baixa renda.

Para esses mesmos autores (2002) o empreendedorismo social difere do empreendedorismo de negócios em dois aspectos. Em primeiro lugar, por não produzir bens e serviços para vender, mas para solucionar problemas sociais; e em segundo lugar, por ser direcionado não somente ao mercado, mas para segmentos populacionais em situação de risco social, como a exclusão social, pobreza, miséria e risco de vida.

Neste panorama de mudanças, Bessant e Tidd (2009) ressaltam a figura do empreendedor social como de extrema importância para a organização, pois este tipo de líder age como propulsor de mudanças atuando com paixão e determinação para a realização de projetos inovativos. Eles estão sempre buscando a mudança, reagem a ela, e a exploram como oportunidades.

Os empreendedores sociais possuem características distintas dos empreendedores de negócios. Eles criam valor social pela inovação, pela força de recursos financeiros em prol do desenvolvimento social, econômico e comunitário. Para Drucker (2008) dentre as suas principais características destaca-se o fato de serem ambiciosos, estratégicos, habilidosos e voltados para a geração de resultado, "fazer do mundo um lugar melhor".

Nesta linha de pensamento, de acordo com Bessant e Tidd (2009) o empreendedorismo social refere-se ao trabalho realizado pelo empreendedor social que reconhece um problema social e utiliza ferramentas e princípios da administração tradicional para resolvê-lo. O seu foco de atuação difere do empreendedorismo tradicional, pois busca essencialmente gerar "valor social" ao invés de criar riqueza pessoal para o acionista.

$\mathrm{O}$ empreendedorismo social apresenta-se como um conceito em desenvolvimento, mas com características teóricas, metodológicas e estratégicas próprias, sinalizando diferenças entre uma gestão social tradicional e uma empreendedora (OLIVEIRA, 2004).

O desafio de buscar novas oportunidades para a gestão do empreendedorismo social faz com que os empreendedores passem a monitorar e comunicar seu interesse para além da simples geração de lucros. Neste sentido, a responsabilidade social corporativa está se tornando uma questão importante em vários negócios, mobilizando-os para a apresentação de "triplo resultado" (sociais, econômicos e ambientais). A apresentação e divulgação de tais resultados visa atender a crescente pressão dos atores sociais por negócios socialmente responsáveis.

Diante dessa colocação, Bessant e Tidd (2009) consideram que a gestão do empreendedorismo social requer o gerenciamento de muitos desafios. Entre eles está o da busca constante por novas oportunidades, selecionar 
estrategicamente a melhor ideia, implementar as atividades de forma criativa, possuir estratégia de inovação por meio de uma visão total e um claro planejamento das ações, atuar de maneira organizada, primando sempre pela busca de redes de trabalho como poderosos vínculos que combinados resultam em parcerias ganha-ganha por meio de projetos inovadores que tanto contribuem para o bem-estar social quando para a obtenção de lucros.

\section{Lócus do estudo: $2^{\circ}$ Feira Mundial de Economia Solidária}

A $2^{\mathbf{o}}$ Feira Mundial de Economia Solidária constitui-se em um evento que congrega as forças da economia solidária e agricultura familiar do Rio Grande do Sul, do Brasil, da América Latina e de outros Continentes. Configura-se como uma rede que a cada ano se fortalece mais e tem como objetivo principal afirmar, em nível mundial, a economia solidária como uma estratégia de desenvolvimento, promover e difundir este modelo de desenvolvimento solidário, sustentável, autogestionário, popular e coletivo, integrando democracia política, econômica, social e ambiental com enfoque em gênero e diversidade cultural, articulando com organizações sociais e solidárias, com a certeza de que outra economia já acontece.

No ano de 2013, a Feira realizou-se na cidade de Santa Maria, Rio Grande do Sul, coordenada pelo Projeto Esperança/Cooesperança da Arquidiocese de Santa Maria, Banco da Esperança, Prefeitura Municipal de Santa Maria, contando com o apoio de várias organizações e com a participação dos Empreendimentos da Economia Solidária, Entidades, de Organizações e do Poder Público. Constitui-se também como uma das ramificações do Fórum Social Mundial (FMS), sendo organizada por um grande Mutirão, por meio de Comissões de Trabalho Autogestionário.

A trajetória do Projeto Esperança/Cooesperança, promotor do evento, iniciou-se em 1994 completando em 2013 vinte anos de existência. Ao realizar uma perspectiva histórica do Projeto, destacam-se as seguintes datas e acontecimentos, como importantes impulsionadores para que o evento ganhasse notoriedade em nível mundial: (i) em1998 a Feira tomou cunho Estadual; (ii) em 2000 passou a ser considerada Feira Nacional; (iii) em 2005 como a Feira do Mercosul; e (iv) em 2007 a Feira passou a ter abrangência Latino Americana, com articulação Intercontinental.

De acordo com dados atualizados pelo Projeto Esperança/Cooesperança, neste ano de 2013, vinte e sete países estiveram representados na Feira, sendo eles: África do Sul, Alemanha, Argentina, Brasil, Bolívia, Canadá, Chile, Colômbia, Cuba, El Salvador, Espanha, Estados
Unidos, Equador, França, Filipinas, Hungria, Itália, Marrocos, México, Nicarágua, Paraguai, Peru, Portugal, República Tcheca, Senegal, Suíça e Uruguai. Além disso, todos os estados brasileiros enviaram representantes, num total de 530 municípios. Mais de mil empreendimentos de Economia Solidária estiveram presentes, oferecendo mais de 10 mil variedades de produtos e serviços. A Feira contou com a participação de aproximadamente $200 \mathrm{mil}$ pessoas.

Diante do exposto, a Feira configura-se como um grande espaço de articulação, debate, troca de ideias, experiências de comercialização direta dos empreendimentos solidários, da agricultura familiar, das agroindústrias familiares, dos catadores/as, dos povos indígenas, dos trabalhadores/as do campo e da cidade, atuando na metodologia autogestionária, do FSM e na construção de "um outro mundo possível".

Ademais, caracteriza-se também como um ambiente de articulação Nacional e Internacional, na qual o trabalho e a organização solidária, por meio do Fórum Brasileiro de Economia Solidária (FBES) e dos Fóruns Regionais da Economia Solidária (FRES), estão acima do capital, motivando assim a consciência de um comércio justo, consumo ético e solidário, no fortalecimento da segurança alimentar nutricional sustentável, firmando práticas e convicções importantes, como a não comercialização de produtos com aditivos químicos, agrotóxicos, nenhum tipo de refrigerante ou cerveja industrializada, e nem o consumo de cigarros; motivando o consumo de produtos naturais, ecológicos como, por exemplo, sucos, caldo de cana, água potável, alimentação sadia e natural, em favor da qualidade de vida e saúde dos consumidores.

\section{Método do Estudo}

No intuito de atender o objetivo proposto, este estudo caracteriza-se quanto ao tipo, como pesquisa descritiva, pois visa descrever os diferentes posicionamentos sobre as temáticas estudadas (VERGARA, 2006). Em relação à abordagem, como qualitativa, que segundo Richardson $(2008$, p. 80) "os estudos que empregam uma metodologia qualitativa podem descrever a complexidade de determinado problema, analisar a interação de certas variáveis, compreender e classificar processos dinâmicos vividos por grupos sociais".

A pesquisa foi realizada no mês de Julho de 2013, na $2^{\circ}$ Feira Mundial de Economia Solidária, por esta se caracterizar com um grande evento que reúne empreendedores sociais de diferentes países. A escolha dos países participantes ocorreu em função da disponibilidade e interesse dos indivíduos em participar do 
estudo, sendo entrevistados representantes do Peru, Argentina, Uruguai e Brasil.

Para a coleta de dados primários, utilizou-se como instrumento um roteiro de entrevista semiestruturado composto por 30 perguntas abertas, elaborado pelos pesquisadores a partir da literatura. $\mathrm{O}$ instrumento de pesquisa foi subdividido em três blocos: o primeiro bloco apresentou 09 questões com o propósito de identificar o perfil da organização; o segundo, continha 05 questões que visavam identificar o perfil das entrevistadas; e o terceiro estava composto por 16 questões específicas ao interesse da pesquisa.

Foram entrevistados os responsáveis pelos empreendimentos de cada um dos países participantes da pesquisa, considerando o conhecimento e o tempo de atuação na organização. As entrevistas com duração em média de 45 minutos foram gravadas e posteriormente transcritas.
Para o tratamento e a análise dos dados utilizouse da técnica de análise de conteúdo (BARDIN, 210) incluindo a organização de categorias de análise.

Segundo Bardin (2010) esta técnica funciona por meio da divisão do texto em partes distintas, em categorias de acordo com um reagrupamento analógico. A categorização oferece diferentes possibilidades de aplicação, tendo sido escolhida a investigação dos temas e/ou análise temática.

Trata-se, em síntese, de uma forma de analisar os dados, a partir da organização, das evidências encontradas, em categorias (MILES e HUBERMAN, 1994). Desta forma, optou-se em desenvolver constructos que seriam as categorias maiores, enquanto as variáveis seriam suas subcategorias, conforme apresentado no Quadro 1.

Além de destacar dentro das variáveis os principais pontos chaves que emergiram nas entrevistas, elaborando-se quadros para uma melhor visualização desses.

Quadro 1: Matriz de agrupamento conceitual ou categorias analíticas

\begin{tabular}{|l|l|}
\hline \multicolumn{1}{|c|}{ Constructos } & \multicolumn{1}{c|}{ Variáveis } \\
\hline \multirow{4}{*}{ Economia Solidária } & Concepção \\
\cline { 2 - 2 } & Gestão da organização \\
\cline { 2 - 2 } & Relações (associados, organizações) \\
\cline { 2 - 2 } & Perspectivas \\
\cline { 2 - 2 } & Informações e atualizações \\
\hline \multirow{4}{*}{ Empreendedorismo Social } & Agente de desenvolvimento social \\
\cline { 2 - 2 } & Orientação para mudanças sociais \\
\cline { 2 - 2 } & Cidadania responsável \\
\cline { 2 - 2 } & Valores (econômico social e ambiental) \\
\hline
\end{tabular}

Fonte: Elaborado pelos autores

A seguir apresentam-se a análise e discussão dos resultados, à luz do referencial teórico.

\section{Análise e Discussão dos Resultados}

Esta seção apresenta os resultados e evidências empíricas da pesquisa.

\subsection{Caracterização dos empreendimentos}

No Quadro 2 estão relacionadas as principais características dos empreendimentos pesquisados. 
Quadro 2-Caracterização dos empreendimentos

\begin{tabular}{|c|c|c|c|c|c|}
\hline País & $\begin{array}{c}\mathrm{N}^{\mathbf{0}} \text { de } \\
\text { empreendimento } \\
\text { s envolvidos }\end{array}$ & $\begin{array}{l}\text { Principal } \\
\text { segmento }\end{array}$ & $\begin{array}{c}\text { Ano de } \\
\text { fundaçã } \\
\text { o }\end{array}$ & $\begin{array}{l}\text { Principais } \\
\text { Produtos }\end{array}$ & $\begin{array}{l}\text { Tempo de atuação na } \\
\text { Economia Solidária }\end{array}$ \\
\hline Peru & $\begin{array}{c}\text { Sete } \\
\text { empreendimentos }\end{array}$ & Artesanato & 2009 & $\begin{array}{l}\text { Artesanato } \\
\text { em tecido }\end{array}$ & Quatro anos \\
\hline Uruguai & $\begin{array}{c}\text { Quinhentos } \\
\text { empreendimentos }\end{array}$ & $\begin{array}{l}\text { Artesanato } \\
\text { e alimento }\end{array}$ & 2000 & $\begin{array}{l}\text { Produtos } \\
\text { orgânicos e } \\
\text { vários } \\
\text { produtos de } \\
\text { artesanato }\end{array}$ & Treze anos \\
\hline Argentina & $\begin{array}{c}\text { Sessenta } \\
\text { empreendimentos }\end{array}$ & $\begin{array}{l}\text { Artesanato } \\
\mathrm{e} \\
\text { perfumaria }\end{array}$ & 2001 & $\begin{array}{c}\text { Facas, roupas } \\
\text { e } \\
\text { Perfumes }\end{array}$ & Sete anos \\
\hline Brasil & $\begin{array}{c}\text { Trinta e nove } \\
\text { empreendimentos }\end{array}$ & Artesanato & 2006 & $\begin{array}{l}\text { Produtos para } \\
\text { decoração de } \\
\text { ambientes, } \\
\text { acessórios }\end{array}$ & Um ano \\
\hline
\end{tabular}

Os empreendimentos de diferentes países participantes do $2^{\circ}$ Fórum Social Mundial de Economia Solidária têm como principal segmento o artesanato. Percebe-se que a maioria está no mercado há mais de cinco anos, evidenciando a experiência dos empreendimentos pesquisados nesta atividade.
6.2 Perfil dos entrevistados

O Quadro 3 apresenta as características em relação ao perfil dos entrevistados.

\begin{tabular}{|l|l|l|l|l|}
\hline \multicolumn{1}{|c|}{ País } & \multicolumn{1}{|c|}{ Idade } & \multicolumn{1}{c|}{ Sexo } & $\begin{array}{l}\text { Tempo de atuação no } \\
\text { empreendimento }\end{array}$ & \multicolumn{1}{c|}{ Escolaridade } \\
\hline Peru & Quarenta anos & Feminino & Quatro anos & $3^{\circ}$ completo \\
\hline Uruguai & Quarenta anos & Feminino & Sete anos & $2^{\circ}$ completo \\
\hline Argentina & $\begin{array}{l}\text { Cinquenta e cinco } \\
\text { anos }\end{array}$ & Feminino & Treze anos & $2^{\circ}$ incompleto \\
\hline Brasil & Cinquenta anos & Feminino & Sete anos & $2^{\circ}$ completo \\
\hline
\end{tabular}

Pode-se observar a partir do Quadro 3 que as entrevistadas foram todas do sexo feminino, característica marcante dos participantes dos empreendimentos e apenas uma das entrevistadas possui ensino superior.

\subsection{Economia solidária \\ Concepção de economia solidária}

A concepção de economia solidária na visão dos entrevistados está sintetizada em palavras chaves, conforme dispostas no Quadro 4. 
Quadro 4 - Concepção de Economia Solidária

\begin{tabular}{|c|c|}
\hline Países & Concepção de Economia Solidária \\
\hline \multirow[t]{2}{*}{ Peru } & Trabalho coletivo \\
\hline & Comercialização dos produtos \\
\hline \multirow{3}{*}{ Uruguai } & Construção coletiva \\
\hline & Pessoas como centro do trabalho \\
\hline & Equidade \\
\hline \multirow{4}{*}{ Argentina } & Ajudar um aos outros \\
\hline & Troca de experiências \\
\hline & Comercialização dos produtos \\
\hline & Autogestão \\
\hline \multirow{3}{*}{ Brasil } & Trabalho coletivo \\
\hline & Geração de renda \\
\hline & Qualidade de vida para comunidade \\
\hline
\end{tabular}

Os resultados evidenciam que na maior parte dos empreendimentos pesquisados, independente do país de origem, a economia solidária é percebida como uma construção coletiva, na qual as pessoas são o foco principal. A entrevistada responsável pelo empreendimento do Peru relatou "[...] A economia solidária é importante, pois antes trabalhávamos individualmente e agora todas as mulheres trabalham grupalmente e há uma ajuda mútua entre todas participantes do empreendimento [...]". Verificou-se que a principal motivação das participantes do empreendimento do Peru no envolvimento com a economia solidária, foi minimizar questões como "machismo" e a "discriminação feminina" que impera no país.
Já a responsável pelo empreendimento do Uruguai destacou que a economia solidária é uma forma de transformar a sociedade, em uma sociedade mais igualitária. Corroborando o pensamento de autores como Oliveira (2003) quando afirma que por meio da economia solidária, criam-se alternativas que quebram o ciclo de crescimento da pobreza e da exclusão social.

\section{Gestão dos empreendimentos}

No Quadro 5 apresentam-se as principais questões relativas à gestão dos empreendimentos, com enfoque em destacar como são realizados, quem participa, entre outras.

\section{Quadro 5 - Gestão dos empreendimentos}

\begin{tabular}{|l|l|}
\hline \multicolumn{1}{|c|}{ País } & Gestão dos empreendimentos \\
\hline \multirow{2}{*}{ Peru } & Cada grupo cuida do seu empreendimento \\
\cline { 2 - 2 } & Encontram-se para comercializar \\
\hline \multirow{4}{*}{ Uruguai } & Coordenação do projeto \\
\cline { 2 - 2 } & Um executivo e os delegados eleitos \\
\cline { 2 - 2 } Argentina & Todos voluntários \\
\hline \multirow{5}{*}{ Brasil } & Cada responsável cuida do seu empreendimento \\
\cline { 2 - 2 } & $\begin{array}{l}\text { Cooperativa (legalizada) } \\
\text { Diretoria (5 membros); Conselho fiscal (titulares e } \\
\text { suplentes) }\end{array}$ \\
\cline { 2 - 2 } & $\begin{array}{l}\text { Todos os produtos (produzidos e comercializados no } \\
\text { coletivo) }\end{array}$ \\
\cline { 2 - 2 } & Controle de entradas e saídas \\
\hline
\end{tabular}

A autogestão prevalece nos empreendimentos, ou seja, onde todos os envolvidos participam de forma construtiva. Este resultado vem ao encontro de França (2003) que salienta que a 
economia solidária deveria ser considerada como uma concepção de gestão, pois reconhece e incorpora a importância da dimensão estratégica na ação organizacional e busca valorizar o sentido público dessa ação.
Quando questionados sobre a forma como o empreendimento relaciona-se com outras organizações e associados, emergem como principais pontos os destacados no Quadro 6.

\section{Relações entre associados e empreendimentos}

Quadro 6-Relações dos empreendimentos

\begin{tabular}{|c|l|}
\hline \multicolumn{1}{|c|}{ País } & Relações entre associados e empreendimentos \\
\hline \multirow{2}{*}{ Peru } & Para comercializar \\
\cline { 2 - 2 } & Participação em feiras \\
\hline \multirow{4}{*}{ Uruguai } & Instituições de apoio \\
\cline { 2 - 2 } & Associações de mulheres \\
\cline { 2 - 2 } & Outros empreendimentos de economia solidária \\
\hline \multirow{4}{*}{ Argentina } & Outros empreendimentos \\
\cline { 2 - 2 } & Coletivo \\
\cline { 2 - 2 } & Troca de experiências \\
\hline \multirow{2}{*}{ Brasil } & Construção de parcerias \\
\cline { 2 - 2 } & Entre grupos de economia solidária de municípios e estados \\
\hline
\end{tabular}

A principal relação dos empreendimentos ocorre com seus parceiros para troca de experiências, de informações, busca de apoio nos projetos dos empreendimentos e algumas vezes recursos para participações em feiras.

O empreendimento do Peru relata que "[...] existe uma parceria com uma organização governamental da Espanha, eles enviam ajuda, por exemplo, para vir até a feira, pagaram as passagens e hospedagem [...]". Diante do exposto, verifica-se que, de acordo com Coutinho et al. (2005), a economia solidária representa um local de diálogo, solidariedade e cooperativismo para os participantes.

\section{Perspectivas em relação à economia solidária}

As perspectivas em relação à economia solidária em cada um dos países e os principais pontos encontram-se dispostos no Quadro 7.

Quadro 7 - Perspectivas em relação à economia solidária

\begin{tabular}{|c|l|}
\hline País & Perspectivas em relação à economia solidária \\
\hline \multirow{2}{*}{ Peru } & Construção de mais feiras \\
\cline { 2 - 2 } & Necessidade de uma maior divulgação \\
\cline { 2 - 2 } & Acelerar o processo de crescimento \\
\hline \multirow{2}{*}{ Uruguai } & Encontra-se em fase de crescimento \\
\hline \multirow{2}{*}{ Argentina } & Necessidade de uma maior divulgação \\
\cline { 2 - 2 } & Possibilidade de maior acesso às discussões \\
\hline Brasil & Precisa de uma maior divulgação e atenção \\
\hline
\end{tabular}


Verifica-se que em todos os empreendimentos pesquisados a economia solidária está crescendo aos poucos, ou seja, está em desenvolvimento. A entrevistada do empreendimento do Brasil relatou que hoje já existe maior atenção e discussão sobre o tema. Expõe ainda que na cidade de São Luís no Maranhão onde se localiza o empreendimento foi criada uma secretaria municipal de economia solidária. No depoimento da responsável pelo empreendimento da Argentina ela descreve que "[...] $\mathrm{Na}$ faculdade de Quilmes em Santa Fé há um grupo de estudantes que realizam debates e divulgam a economia solidária, mas ainda precisa-se de uma maior divulgação por parte do governo [...]". A responsável pelo empreendimento do Uruguai respondeu "[...] Precisase de uma maior visibilidade dos empreendimentos, conversar com as pessoas que tomem consciência do que é a economia solidária, criar mais redes de economia solidária em todo país [...]".

\section{Informações e atualizações}

No Quadro 8 demonstra-se um resumo dos locais onde os empreendimentos buscam as informações sobre economia solidária.

Quadro 8-Informações em relação à economia solidária

\begin{tabular}{|c|l|}
\hline País & Informações e atualizações \\
\hline \multirow{4}{*}{ Peru } & Reuniões \\
\cline { 2 - 2 } & Universidades \\
\cline { 2 - 2 } & Internet \\
\hline \multirow{4}{*}{ Uruguai } & Internet \\
\cline { 2 - 2 } & Eventos \\
\hline \multirow{4}{*}{ Argentina } & Internet \\
\cline { 2 - 3 } & Reuniões \\
\hline \multirow{3}{*}{ Brasil } & Parceiros \\
\cline { 2 - 2 } & Feiras \\
\cline { 2 - 2 } & No município \\
\hline
\end{tabular}

Entre as principais fontes de busca de informações e atualizações sobre economia solidária destaca-se a internet. Para alguns empreendimentos, como no Peru e na Argentina, as reuniões são essenciais. A representante do empreendimento do Uruguai relatou "[...] as feiras em especial as internacionais é uma forma de fortificar a discussão e importância da economia solidária, juntos com os outros empreendimentos de países diferentes [...]". A entrevistada do empreendimento brasileiro enfatizou as feiras como uma forma de divulgação do trabalho e troca de informações e experiências.

\subsection{Empreendedorismo Social Agente de desenvolvimento social}

No Quadro 9 evidenciam-se os principais pontos destacados pelas entrevistadas quando questionadas a respeito da organização buscar ser um agente do desenvolvimento social e de que forma procede esta busca. 
Quadro 9-Agente de desenvolvimento social

\begin{tabular}{|c|c|}
\hline Países & Agente de desenvolvimento social \\
\hline Peru & Proporciona autonomia das mulheres da comunidade \\
\hline Uruguai & Praticando a economia solidária \\
\hline Argentina & Proporcionam cursos para comunidade \\
\hline \multirow{2}{*}{ Brasil } & Fortalecimento das mulheres da comunidade \\
\cline { 2 - 2 } & Melhoria na qualidade de vida das artesãs \\
\hline
\end{tabular}

Em relação aos empreendimentos do Peru e do Brasil pode-se verificar que a questão de gênero é marcante, uma vez que os dois empreendimentos são compostos somente de mulheres. Percebe-se que há uma preocupação em fortalecer a relação das mulheres com a sociedade, principal característica apontada nos dois empreendimentos como agente de desenvolvimento social. "[...] ajudamos as mulheres da comunidade a serem autos suficientes e não depender de seus esposos [...]" apreciação relatada pela responsável do empreendimento do Peru. Já a entrevistada brasileira relatou que "[...] a partir do momento que nos organizamos para trabalhar juntas, onde se juntou um grupo de mulheres, melhorou com a qualidade de vida da própria comunidade [...]". Estas declarações corroboram com o exposto por Bessant e Tidd (2009) ao defender que o empreendedorismo social refere-se ao trabalho realizado pelo empreendedor social que reconhece um problema social e utiliza ferramentas e princípios da administração tradicional para resolvê-los.

\section{Orientação para mudanças sociais}

No Quadro 10 apresentam-se os aspectos relacionados à orientação dos empreendimentos para mudanças sociais significativas.

\section{Quadro 10 - Orientações para mudanças sociais}

\begin{tabular}{|c|c|}
\hline Países & $\begin{array}{c}\text { Orientação para mudanças } \\
\text { sociais }\end{array}$ \\
\hline \multirow{2}{*}{ Peru } & Mulheres empreendedoras \\
\cline { 2 - 2 } & $\begin{array}{c}\text { Participação das mulheres no } \\
\text { mercado de trabalho }\end{array}$ \\
\hline Uruguai & Através das capacitações \\
\hline Argentina & $\begin{array}{c}\text { Reuniões para discutir as } \\
\text { questões sociais da comunidade }\end{array}$ \\
\hline Brasil & Por meio das capacitações \\
\hline
\end{tabular}

Observou-se que as respostas foram semelhantes aos relatos em relação ao quesito agente de desenvolvimento social, até por estarem próximos à orientação de mudanças sociais. A entrevistada do empreendimento do Peru relata "[...] somos dirigentes da comunidade, apontamos o que precisa melhorar na comunidade e algumas vezes quando é possível resolvemos os problemas da comunidade [...]". A entrevistada do Brasil, por sua vez, declarou que "[...] por meio das capacitações se proporciona consciência do trabalho desenvolvido e da importância para a comunidade, além da troca de informações e ajuda entre as artesãs [...]". Os relatos das entrevistadas estão de acordo com a explanação de Madruga (2009) ao inferir que para reso ver problemas sociais é necessário desenvolver iniciativas com potencial de inovação social transformadora de uma realidade local, nacional ou mundial.

\section{Cidadania responsável}

No Quadro 11 destacam-se os principais tópicos relacionados ao questionamento sobre o empreendimento promover uma cidadania responsável. 
Quadro 11 - Cidadania responsável

\begin{tabular}{|c|c|}
\hline País & Cidadania responsável \\
\hline \multirow{2}{*}{ Peru } & Respeito mútuo \\
\cline { 2 - 2 } & Projetos sociais \\
\cline { 2 - 2 } & $\begin{array}{c}\text { Projetos com recicladores } \\
\text { Arguaimentos em prol das } \\
\text { mulheres }\end{array}$ \\
\hline \multirow{2}{*}{ Brasil } & $\begin{array}{c}\text { Projetos para geração de } \\
\text { renda na comunidade }\end{array}$ \\
\cline { 2 - 2 } & $\begin{array}{c}\text { Compartifundir a cultura } \\
\text { com outras compecimento }\end{array}$ \\
\hline
\end{tabular}

Observou-se que todos os empreendimentos de alguma forma praticam a cidadania responsável. O empreendimento do Brasil destacou o trabalho que realizam para difundir a cultura da sua região na comunidade onde estão inseridos. "[...] a partir do momento que trabalhamos com a questão da cultura, divulgando nas escolas com crianças desde pequenas para que cresçam dando valor a sua própria cultura e repassando esses conhecimentos para toda a comunidade, também proporcionamos oficinas voluntariamente para a comunidade [...]". Já a representante do empreendimento do Peru destacou os projetos sociais "[...] temos um projeto social chamado "comedouros sociais", no qual fazemos comida para as crianças. Isto porque muitas vezes as mulheres da comunidade trabalham e não conseguem ir para casa fazer comida para suas crianças $[\ldots] "$ ".

\section{Valores econômicos, sociais e ambientais}

Inseridas em um ambiente competitivo e em constantes transformações as organizações são instigadas a desenvolver valores econômicos, sociais e ambientais. Ao considerar este cenário, as representantes dos empreendimentos foram questionadas sobre a forma pela qual são considerados estes valores nos empreendimentos.

Quadro 12 - Valores econômicos, sociais e ambientais

\begin{tabular}{|l|l|}
\hline \multicolumn{1}{|c|}{ Peru } & \multicolumn{1}{c|}{ Equilíbrio entre os três valores } \\
\hline \multirow{4}{*}{ Uruguai } & Social é considerado o principal \\
\cline { 2 - 2 } & Ambiental está sendo trabalhado \\
\cline { 2 - 2 } & Econômico é uma consequência do trabalho desenvolvido \\
\hline \multirow{4}{*}{ Brgentina } & Social é considerado o principal \\
\cline { 2 - 2 } & Econômico é uma consequência do trabalho desenvolvido \\
\cline { 2 - 2 } & Ambiental tem que ser melhorado \\
\hline & Social é o principal \\
\cline { 2 - 2 } & Ambiental há uma preocupação \\
\cline { 2 - 2 } & Econômico é uma consequência do trabalho desenvolvido \\
\hline
\end{tabular}

No Quadro 12 verificou-se que todos os empreendimentos consideram o valor social como o mais trabalhado, já o ambiental apesar de a maioria ter consciência da importância, ainda precisa ser mais desenvolvido por parte dos associados. O econômico é uma consequência de todo o trabalho desenvolvido nos empreendimentos, decorrente da comercialização dos produtos. A responsável pelo empreendimento do Peru relatou "[...] tentamos trabalhar as três dimensões, ambiental, social e econômico, consideramos importante o equilíbrio dos três $[. .$.$] ". A entrevistada do Uruguai declarou$ que "[...] o valor social é o principal, ao considerar uma das principais características da economia 
solidária, mas, no entanto, estamos tentando trabalhar a questão ambiental por meio do uso de matéria prima que não prejudique o meio ambiente [...]".

O valor ambiental é o que mais precisa ser trabalhado nos empreendimentos "[...] existe uma falta de consciência ambiental [...]", relatou a responsável pelo empreendimento da Argentina." $[\ldots . .$. .Por outro lado, para o empreendimento do Brasil o social é o principal valor trabalhado e caracteriza-se como uma consequência das discussões e do objetivo da economia solidária. "[...]O valor ambiental é trabalhado de forma contínua, por exemplo, a matéria prima é extraída basicamente da natureza, por isso, há um cuidado com a preservação ambiental $[\ldots] "$.

Diante do exposto, pode-se verificar que os empreendimentos, independente de seu país de origem, possuem concepções semelhantes a respeito da economia solidária. Um fator que os diferencia está na motivação para participar do fenômeno social de economia solidária. Observou-se que, para o empreendimento do Peru, foi o movimento da luta das mulheres, o do Uruguai uma forma de tornar a comunidade mais igualitária, o da Argentina na construção do coletivo e o do Brasil, o ingresso das mulheres no mercado de trabalho e fortalecimento da cultura local.

\section{Conclusões}

A partir dos resultados deste estudo verificouse que a maioria dos entrevistados considera a economia solidária como uma construção do coletivo, da equidade e da solidariedade, além de ser uma maneira de ter seu próprio empreendimento, ou seja, desenvolver ou potencializar suas características de empreendedores sociais.

A autogestão é uma das principais características na gestão dos empreendimentos, na qual todos participam de forma democrática e construtiva, o que vem a corroborar com a teoria. No que diz respeito às relações com associados e outros empreendimentos destacam-se as trocas de experiências para comercializar os produtos, apoio e parcerias. No que se refere à perspectiva da economia solidária, identificou-se que em todos os países precisa haver uma maior divulgação da economia solidária, enquanto para alguns países está em fase de desenvolvimento, para outros como no Peru ainda é incipiente.

Em relação às informações, são basicamente oriundas de reuniões, internet e as próprias feiras onde é um ponto de discussão e troca de experiências. No que tange as características de empreendedorismo social, todos os empreendimentos de alguma forma trabalham na busca da cidadania responsável, orientação para mudanças sociais e agentes de desenvolvimento local. O empreendimento do Peru, por exemplo, possui um trabalho forte de inserção da mulher na sociedade e no mercado de trabalho proporcionado a autonomia dessas. A maioria possui projetos na comunidade onde estão inseridos.

Já a questão de como é trabalhado os valores sociais, ambientais e econômicos, só o empreendimento do Peru busca o equilíbrio entre os três valores, nos outros empreendimentos o social é o mais desenvolvido, estando assim de acordo com os ditames da economia solidária, na qual o foco no social caracteriza-se como o principal.

Esse estudo oportuniza a constatação empírica dos preceitos ditados pela teoria acerca da economia solidária na visão de diferentes empreendedores sociais da América Latina. Dentre as limitações do estudo, mencionam-se a dificuldade de aplicar as entrevistas, devido ao grande público visitante na feira. As pessoas responsáveis pelos empreendimentos não dispunham de tempo disponível, pois precisavam atender os clientes e participar dos fóruns.

Recomendam-se novos estudos que possibilitem uma amplitude maior de entrevistados, inclusive abrangendo outros empreendimentos, de outros países visto que a feira configura-se como de abrangência mundial. Também se identificam como lacunas o desenvolvimento de estudos sobre a concepção de economia solidária em diferentes regiões do Brasil e até mesmo uma pesquisa sobre o viés dos consumidores participante da feira.

\section{Referências}

ANDION, C. A Gestão no Campo da Economia Solidária: Particularidades e Desafios. Revista de Administração Contemporânea , v. 9, n. 1, Jan./Mar. 2005. 
BARDIN, L. Análise de conteúdo.4.ed. Lisboa: Edições 70, 2010.

BESSANT, J.; TIDD, J. Inovação e empreendedorismo. Porto Alegre: Bookman, 2009.

COUTINHO, C. M; BEIRAS, A; PICININ, D; LUCKMANN, L. G. Novos Caminhos, Cooperação e Solidariedade: A Psicologia em Empreendimentos Solidários. Revista Psicologia \& Sociedade; 17 (1): 17-28; jan/abr.2005.

DRUCKER, P. F. Inovação e espírito empreendedor: prática e princípios. São Paulo: Pioneira Thomson, 2008.

FRANÇA FILHO, G. C; LAVILLE, J. L. Economia Solidária uma abordagem internacional. Porto Alegre: UFRGS, 2004.

FRANÇA FILHO, G. C. A temática da economia solidária e suas implicações originais para o campo dos estudos organizacionais. RAP. Rio de Janeiro, 37(1):11-31, Jan./Fev. 2003.

GAIGER, 1. I. A economia solidária e o projeto de outra mundialização.Revista de Ciências Sociais, Rio de Janeiro, Vol. 47, no 4, 2004, pp. 799 a 834.

MADRUGA, L. R. R. G. Comportamento Coletivo e Interações Sociais no Comitê de Gerenciamento da Bacia Hidrográfica do Rio Santa Maria: Aprendizagem Social e Emergência do Empreendedorismo Socioambiental. Tese (doutorado). Universidade Federal do Rio Grande do Sul, UFRGS, Porto Alegre, 2009.

MELO NETO, F. P.; FROES, C. Gestão da Responsabilidade Social Corporativa:O caso brasileiro. Rio de Janeiro: Qualitymark, 2001.

MELO NETO, F. P. de; FROES, C. Empreendedorismo social: a transição para a sociedade sustentável.Rio de Janeiro: Qualitymark, 2002.

MILES, M. B. HUBERMAN, A. M. Qualitative Data Analysis:AnExpandedSourcebook. London: Sage, 1994.
OLIVEIRA, E. M. Empreendedorismo social no Brasil: atual configuração, perspectivas e desafios notas introdutórias. Revista FAE, Curitiba, v. 7, n. 2, p. 9-18, jul./dez. 2004.

PROJETO ESPERANÇA/COOESPERANCA. II Fórum Social 2013. Disponível em: <http://www.esperancacooesperanca.org.br/>. Acesso em: jul. 2013.

RICHARDSON, R. J. Pesquisa social:Métodos e Técnicas. São Paulo: Atlas, 2008.

ROCA, H; O. Economía solidaria y pueblos indígenas: Desafios para El buen vivir em La región. In: LIANZA, S; HENRIQUES, F. C (Orgs). A economia solidária na América Latina: realidades nacionais e políticas públicas. Rio de Janeiro: Pró Reitoria de Extensão UFRJ, 2012.

SINGER, P; SOUZA. R. A.(Org.). A Economia Solidária no Brasil: A autogestão como resposta ao desemprego. São Paulo: Contexto, 2000. - (Coleção Economia).

TAUILE, R. J. Do socialismo de mercado à economia solidária. Revista de Economia Contemporânea, Rio de Janeiro, v.6, n.1, p. 107-122, Jan./Junh. 2002.

VERGARA, S. C.Projetos e relatórios de pesquisa em administração. São Paulo: Atlas, 2006 
